\title{
Ilaria Vitali, Marivaudage ou tchatche? Jeux de masques et travestissements linguistiques dans "L'Esquive" d'Abdellatif Kechiche
}

\section{Carminella Biondi}

\section{(2) OpenEdition Journals \\ Édition électronique \\ URL : http://journals.openedition.org/studifrancesi/6460 \\ DOI : $10.4000 /$ studifrancesi.6460 \\ ISSN : 2427-5856 \\ Éditeur \\ Rosenberg \& Sellier}

\section{Édition imprimée}

Date de publication : 1 novembre 2010

Pagination : 598-599

ISSN : 0039-2944

\section{Référence électronique}

Carminella Biondi, « llaria Vitali, Marivaudage ou tchatche? Jeux de masques et travestissements linguistiques dans "L'Esquive" d'Abdellatif Kechiche », Studi Francesi [En ligne], 162 (LIV | III) | 2010, mis en ligne le 30 novembre 2015, consulté le 10 janvier 2021. URL : http://journals.openedition.org/ studifrancesi/6460 ; DOI : https://doi.org/10.4000/studifrancesi.6460

Ce document a été généré automatiquement le 10 janvier 2021.

\section{cc) (†) $\odot$}

Studi Francesi è distribuita con Licenza Creative Commons Attribuzione - Non commerciale - Non opere derivate 4.0 Internazionale. 


\title{
Ilaria Vitali, Marivaudage ou tchatche? Jeux de masques et travestissements linguistiques dans "L'Esquive" d'Abdellatif Kechiche
}

\author{
Carminella Biondi
}

\section{RÉFÉRENCE}

ILARIA VITALI, MARIVAUDAGE OU TCHATCHE? JEUX DE MASQUES ET TRAVESTISSEMENTS LINGUISTIQUES DANS “L'ESQUIVE” D’ABDELLATIF KECHICHE, «Francofonia», primavera 2009, n. 56, pp. 3-16.

Dans cette étude, Ilaria Vitali analyse les aspects les plus intéressants du film L'Esquive d'Abdellatif Kechiche. L'ouvrage du réalisateur franco-tunisien présente une intrigue très originale: un groupe d'élèves de la banlieue parisienne doit représenter Le Jeu de l'Amour et du hasard de Marivaux. La préparation de ce spectacle permettra aux acteurs protagonistes de la pièce de découvrir un monde nouveau dont ils n'imaginaient même pas l'existence, prisonniers d'un univers gris et apparemment sans espoir. Le film pourrait en effet être lu comme un voyage digne de Jules Verne à la conquête d'un univers parallèle: le premier pas pour conquérir ce nouveau monde est celui de choisir des vêtements typiques de l'époque étudiée pour faciliter la création d'un premier contact visuel et esthétique avec la nouvelle réalité; ensuite, pour comprendre les règles et la mentalité d'un monde inconnu, il faut connaître la langue et les expressions typiques de la société qu'on veut explorer; enfin, il faut vivre l'univers qu'on a analysé à travers l'actualisation des modèles étudiés qui deviendront la base pour modifier ses propres schémas idéologiques.

2 Comme Vitali l'explique, la pièce de Marivaux, avec sa richesse sémantique et langagière, fournit l'axe du film ainsi que son modèle de fonctionnement. Après avoir pénétré dans l'univers magique du théâtre, les jeunes adolescents libèrent, chacun à 
leur manière, leurs émotions: de même que le personnage de la pièce de Marivaux, Krimo/Arlequin tombe amoureux de Lydia/Lisette, qui, pour sa part, «l'esquive» comme son rôle le prescrit. L'amour de Krimo pour Lydia est intimement lié à l'étonnante beauté de l'ambiance théâtrale, au point qu'une fois le spectacle terminé, Krimo se montrera indifférent envers la jeune actrice dont le charme l'avait pourtant ensorcelé lorsqu'il l'avait vue habillée en dame de condition. Dans son article, Vitali réfléchit en premier lieu sur le rôle représenté par les travestissements utilisés par les élèves qui préparent leur spectacle. Elle s'attarde en particulier sur les «masques» des deux personnages principaux du film, Krimo et Lydia, pour montrer de quelle manière ils s'approprient ou ne s'approprient pas les possibilités fournies par les déguisements théâtraux. Si Krimo se révèle tout de suite incapable de jouer le rôle d'Arlequin, d'apprendre et de maîtriser son langage, pour Lydia endosser les vêtements de l'époque de Marivaux - même s'il s'agit de simples costumes de scène réalisés par le couturier du quartier - signifie sortir du monde réel pour pénétrer dans un univers de rêve, qui se détache des règles strictement codées de la cité. En soulignant le rôle du vêtement comme viatique pour sortir d'une réalité pénible, Vitali réfléchit sur le besoin intérieur de fuite, de libération, qui dévore tout individu, et qui semble particulièrement présent dans la réalité des cités de ce début de nouveau millénaire.

3 Après avoir étudié les enjeux du travestissement théâtral, l'auteur propose une analyse très originale $d u$ «travestissement linguistique», en étudiant plusieurs aspects syntaxiques et lexicaux de l'argot des cités, «un sociolecte constitué d'un mélange d'argot, de verlan et d'emprunts aux langues tsiganes, africaines et surtout à l'arabe (notamment dans ses variantes maghrébines)»(p.11), difficilement compréhensible par les non-initiés. À travers de nombreux exemples du langage argotique tirés du film, Vitali montre à quel point cette parlure que les linguistes appellent «français contemporain des cités» n'est pas un simple «langage des rues», mais plutôt une sorte de «marivaudage contemporain». C'est là la partie la plus originale de l'étude de Vitali, qui montre, par ailleurs, que le verlan n'est pas le seul fait du xxI èècle, comme on a tendance à croire: ses origines remontent en fait au Moyen Âge, même si, comme l'auteur l'explique, cette pratique langagière déviante a pris une couleur particulière dans les banlieues franciliennes, où elle semble bien représenter le sentiment de refus et d'exclusion sociale vécu par ses habitants.

4 En analysant L'Esquive au diapason de la pièce de Marivaux, Ilaria Vitali contribue à effacer les stéréotypes sur le monde des banlieues. Au croisement de la sémiotique verbale et non-verbale, l'auteur souligne de quelle manière les stratégies de communication de ces jeunes qui semblent perdus dans une dérive morale et existentielle sont en réalité régies, comme il en était pour Marivaux, par des codes bien précis. La compréhension de ces derniers est donc fondamentale aux «externes» à la cité pour créer des rapports de confiance et de respect réciproque avec ses habitants: rompre le mur des images banales qui résument les personnalités complexes des jeunes des banlieues permet ainsi d'explorer leur monde intérieur où la faiblesse et la peur d'être abandonnés dominent sur l'arrogance et l'agressivité extérieure. Le langage des cités, soulant et déroutant, constitue la clef d'accès à ce monde qui cache sous une vulgarité apparente-Kechiche le montre très clairement-une grande tendresse. «Dans ce vestiaire du verbe que sont les cités de l'île-de-France, le déguisement argotique peut servir, comme Hugo l'affirmait, pour 'commettre une mauvaise action', 
mais peut aussi tenir lieu, comme plusieurs séquences du film le montrent, de marivaudage moderne» (p. 16).

5 À la croisée de la critique littéraire, de la sociologie et de la linguistique, cet article intègre les connaissances de plusieurs savoirs pour montrer le monde des banlieues sous un angle nouveau. Par ailleurs, en comparant depuis plusieurs points de vue les ouvrages de Marivaux et de Kechiche, Vitali se penche sur le pouvoir des classiques et sur la possibilité de leur réinvention à l'époque actuelle, car «loin d'être un simple ajout, la pièce marivaudienne pose le nœud dramatique du film et en donne la clef pour en comprendre les enjeux» (p.4). La modernité de toute œuvre littéraire réside précisément dans la possibilité d'ouvrir une fenêtre plus grande sur l'interprétation du monde. Qui plus est, cette étude nous encourage à croire que la littérature peut encore aider le rêve, car c'est par le biais de Marivaux que les adolescents du film de Kechiche ont l'opportunité de découvrir que d'autres vies sont possibles, au-delà des tours H.L.M. 